\title{
DEVELOPING A STANDARD METHODOLOGY FOR DYNAMIC NAVIGATION IN THE LITTORAL ENVIRONMENT V
}

F Forsman and J Dahlman, Chalmers University, Sweden

T Dobbins, STResearch, UK

\section{SUMMARY}

The safe operation of fast craft within the littoral environment places a high workload on the vessels crew and specifically the navigator, who has to avoid natural features as well as other vessel traffic. This task is subsequently made more difficult by poor weather and sea conditions. Due to the high operational pace and the dynamic nature of transiting the littoral environment, a simple methodology was developed that would be robust in high workload conditions. The model is based on three components; i) the conduct of changes in direction/course, ii) the information required by the coxswain to perform the course change effectively and safely, and iii) the information required by the navigator to plan and direct the course change. This paper will describe the methodology, the concepts behind its development, and how standardised procedures enhance safety, operational effectiveness and interoperability.

\section{NOMENCLATURE}

\begin{tabular}{|c|c|}
\hline HSC & High Speed Craft \\
\hline $\mathrm{C} 2$ & Command and Control \\
\hline C3 & $\begin{array}{l}\text { Command, Control and } \\
\text { Communication }\end{array}$ \\
\hline $\mathrm{HSC} 3$ & $\begin{array}{l}\text { High Speed Craft Command and } \\
\text { Control }\end{array}$ \\
\hline EDCIS & $\begin{array}{l}\text { Electronically Displayed Chart } \\
\text { Information System }\end{array}$ \\
\hline TA & Task Analysis \\
\hline TNA & Training needs Analysis \\
\hline SA & Situational Awareness \\
\hline SAP & Situation Assessment Process \\
\hline SSRS & Swedish Sea Rescue Society \\
\hline DYNAV & Dynamic Navigation \\
\hline SMA & Swedish Maritime Authority \\
\hline RIB & Rigid Inflatable Boats \\
\hline WIG & Wing in Ground \\
\hline SAR & Search and Rescue \\
\hline NDM & Naturalistic Decision Making \\
\hline $\mathrm{COG}$ & Course over ground \\
\hline GPS & Global Positioning System \\
\hline COLREGS & $\begin{array}{l}\text { The International Regulations for } \\
\text { Preventing Collisions at Sea }\end{array}$ \\
\hline
\end{tabular}

\section{INTRODUCTION}

How do we account for the element of movement in navigation? How do we adapt to a new context where speed is a very crucial factor with great effect on the crew's situation.

Movement itself is the foundation that navigation as a concept rests upon. Ships are sailing from one destination to another, movement is fundamental. However, the question that we will address with this paper is how increased speed has effects on methodologies developed among different organisations that operate High Speed Crafts (HSC).
Dobbins (2010) recommends a model of High Speed Craft Command and Control (HSC3) to be developed. In this paper we aim to describe what has been empirically developed among some end users of HSC.

\section{DEFINING THE ISSUE \\ 2.1 CREW TASKS / WORKLOAD}

As the maritime situation gets more and more challenging we need to perform the tasks with more redundancy/spare capacity to avoid accidents/incidents and their consequences. We are arguing that with increasing speed, navigation is an increasing challenge that has to be met in order to maintain an acceptable level of safety for crew and ship.

The increasing speed affects the craft system in many ways. The navigator has less time to assess the situation and make safe and effective decisions than at lower speeds. He also suffers reduced display effectiveness due to repeated shock and vibration. If the situation is complex enough then the navigator will suffer a shortage of time to complete the required tasks. The results being the choice of either slow down or negotiate/accept a reduced level of safety.

If the situation/environment/location is new, or relatively new, the navigator is unlikely to have had the opportunity to gain the experience needed to make good decisions from local knowledge.

This is a typical situation for the majority of relative novices making decisions. It may be argued that one can't always differentiate between an experienced mariner and a novice; it all depends on the situation and whether they have significant experience and/or training in a specific context. No matter how experienced one is one will always encounter new situations and in that perspective be a novice. One can't be trained to cope with every single possible situation one can expect to risk 
to come across but we can train methodologies that enable us to make good decisions in those situations.

The task of driving the boat will alter too. With higher speed comes a greater responsibility, to your own vessel, to others and the surroundings. This is controlled by The International Regulations for Preventing Collisions at Sea (COLREGS) (IMO, 2003) and the laws of the sea. Sometimes it isn't obvious, and an argument that speed on the sea is unlimited can be made, which isn't true. Even though the term "Seamanship" is hard to define, the COLREGS use it in such way that we understand that we have to show respect to our surroundings. The term is also used to address risk taking and safety in such way that it is hard to accept arguments for speed being unlimited. Let us look at the physical circumstances, how the situation for the coxswain change as a vessel does go from low to high speed. Accepting that greater responsibility is linked with higher speed, we then face a more challenging situation when it comes to the look out. We mustn't expect slow going vessels to have their eyes nailed to the horizon trying to identify high-speed-vessels that they should give way to. We understand the world from our own perspective and a slow going vessel will therefore have less understanding for a high speed vessel and vice versa. But the high speed vessel will have a greater responsibility in a situation with a significant slower vessel. This puts a number of questions in focus and especially the look out.

\section{1 (a) Eye Tracking}

Dahlman (2008) shows that self taught leisure sailors did focus more on the instruments, in respect to the environment, when the speed increased from 23 knots to 43 knots. This finding is interesting especially as the other group tested, trained HSC crew, were maintaining the ratio of their fixations between instruments and surroundings. This finding implies that the training undertaken by the HSC crews actually enables them to keep the same relative amount of attention on the surroundings and thus having better conditions to detect threats and avoid collision optically. How this is affecting the crews Situational Awareness (SA) is an interesting issue. But not looking out and forward when the speed increases doesn't seem to be a safe behaviour.

\section{CHRONOLOGICAL DEVELOPMENT}

\subsection{SWEDISH AMPHIBIOUS CORP}

During the late 80:s and early 90:s the Swedish Coastal Artillery went through a fundamental and profound reorientation to become the Amphibious Corpse. The main purpose and tasks for this branch of the Swedish Armed Forces didn't change but the way the goals were achieved did. The goal for both the Coastal Artillery and The Amphibious Corpse was do defend the coastline against invasion from sea. In the days of the Coastal
Artillery one relied on a hard shell strategy and dug deep down into the bedrock of the coastline to build a huge network of artillery and minefields. The cost of this strategy was of cause immense and combined with a new era of high precision weapons the hard shell strategy stared to become outdated and very expensive. The response to this was to change protection for movement and the idea of light, fast and heavily armed battalions as a replacement for the Costal artillery started to become a reality. The idea was to create a unit that could move to an area and set up a defence in a very short period of time. Instead of adapting the well know concept of marines, who come by sea and want to get across the amphibious zone as smooth as possible, the Amphibious Corpse were exclusively to operate in and stay in the transition between water and land. In order to do this they needed fast and very manoeuvrable landing crafts and the answer to this was the Combat Boat 90 .

The fastest boats in the Coastal Artillery, with some exceptions, had had a top speed of approximate 20 knots. The Combat Boat 90 had twice that capacity, could carry 20 troopers and was manned only by three conscripts. The former navigation tradition was built upon how large ships were to be navigated. Even though it probably wasn't the best way of navigating a small vessel in coastal water in speeds up to 20 knots; it suited its purpose well enough. But with the Combat Boat 90 there was not a chance that the crews could use this old school methodology to operate their vessels either safe or efficient. The need for an alternative methodology was imperative. The crew could not simply cope with the task at that speed. The workload for single crewmembers was too high and the process from sensor to action was far too slow. Trough a huge push for development of methodology and training the Amphibious Corpse empirically developed their high speed navigation methodology (Försvarsmaken, 2003) which we will describe in further detail in chapter 4 .

\subsection{SWEDISH SEA RESCUE SOCIETY}

The Swedish Sea Rescue Society (SSRS) has undergone a similar transition as the costal artillery did. The issue here was a change from slow sturdy steal cruisers to small, fast and very manoeuvrable boats not too different from the Combat Boat 90.

The rescue crew were earlier recruited from local fishermen and merchant sailors. They know the trick of the trade and they more or less learned what they needed to know for the rescue task, in their normal trade. The boats they used in their everyday business, lets say fishing boats, weren't very different from the rescue vessel. One can say that at that time and with the societal constraints that there were, there was a good match between the task and the crew competencies.

This has now radically changed. The recruitment base is no longer seamen but rather leisure sailors or novices. 
Combined with a new breed of boats that are capable of four times the speed the older boats and together with some of the most sophisticated technical solutions on the market today, there is a conflict.

Today the SSRS are training their crews in a developed, simplified and adapted version of the high speed navigation methodology and calls it Dynamic Navigation (DYNAV). DYNAV can be seen as a development and an adaption to constraints outside the pure military application and to a broader base of trainees than the Amphibious Corpse focuses on.

\subsection{SWEDISH MARITIME AUTHORITY LEGISLATIONS, TRAINING HIGH SPEED CREW IN COMMERCIAL VESSELS.}

After a number of serious accidents with commercial HSC the Swedish Maritime Authority (SMA) took a close look on how the Amphibious Corpse did their navigation training. After some investigation they put forward legislation that calls for mandatory training for HSC crews, i.e. commercial boats under $24 \mathrm{~m}$ of length. Boats with speed capabilities of above 35 knots were legislated to have one crewmember to undertake a 40 hours practical course in High Speed navigation. If the boat has speed capabilities of 45 knots or more then there must be two crewmembers with adequate training.

The Amphibious Corpse argued that the minimum time needed to get at least some result from the training was tree weeks. The SMA argued that there would be problem to get an acceptance from the users for such demand. What an appropriate amount of training time would be could be argued depending on what the goal is and the starting competence of the trainees. The Amphibious Corpse has had an average of 12 to 14 weeks of practical training at sea, three trainees per boat and instructor. Here we have a huge gap in what's being considered as appropriate amount of training, but there are also large differences in the tasks undertaken by a military boat and a fast commercial vessel.

\subsection{UK Royal Navy / Royal Marines}

A recent attendee of the Swedish High Speed Navigation Course was the Royal Naval Officer in-charge of navigation training at the 10th Landing Craft Training Squadron, Royal Marines. As a result of his attendance and his experiences with UK maritime operations with the RM, an additional annex to the Admiralty Manual of Navigation was written "Assault Navigation"

\section{BASIC METHODOLOGY}

The basic methodology is developed to help the crew to cope with a demanding and dynamic situation. The first element to take account for in the navigation is the speed. Upon that comes mission specific requirement that will add workload to the crew. The methodology utilizes both the driver and the navigator in contrast to normal navigation where a coxswain takes the larger share of the workload. Both have responsibility for the voyage but it is the navigator who has the specific responsibility for the navigation. The navigator isn't a support to the coxswain. In DYNAV the driver is a support to the navigator.

DYNAV creates redundancy and enables the crew to spot their misconceptions or false data before they have influence on safety.

The methodology is designed to be fairly simple. Its purpose is to ad efficiency so one can navigate a route with both higher speed and safety than with conventional methodology.

Is there a complete new paradigm for navigation out there? The short answer is both yes and no. DYNAV doesn't add any new navigation techniques but it gives us a structural methodology that enables the crew to use the right techniques at the right time and help us identify our own mistakes or distorted data before it has implications on safety.

DYNAV is designed to work with all vessels with the current focus being on small Rigid Inflatable Boats (RIB), large planning craft, multi-hulls, Hovercraft and potentially Wing in Grounds (WIG).

The standard is designed to be a robust process that may be adjusted for use with specific craft and situations, e.g. military, security, Search and Rescue (SAR).

The use of a standardized methodology facilitates interoperability between agencies and nations.

Although the process is primarily designed to support Green (Littoral/Coastal) and Brown (Riverine) water environments it can also be used for Blue water operations.

\subsection{DYNAMIC NAVIGATION (DYNAV)}

DYNAV has two main parts:

- The working phases

- Basic navigation information

The phases are of course simplifications of the reality but they serve their purpose by communicating what should be done when to the crew. Each turn or moment is broken down into four parts:

- Plan

- Communicate

- Execute

- Control

(Dobbins, 2010)

This gives the navigator a working methodology to work by. If they are closing up on the next waypoint and the 
crew hasn't finished the closed loop communication it will become very obvious to the crew that have to create more time before the turn i.e. slows down.

The four phases' don't describe the cognitive processes that are taking place very well and should be looked upon as a tool for the crew. As an example of that we can look at the planning phase. The model suggests that planning is just conducted during a brief period of time, which of cause is not true, planning is much more complex, but it serves its purpose by telling the navigator to articulate his plan for himself so it can be told to the driver in the communicating phase.
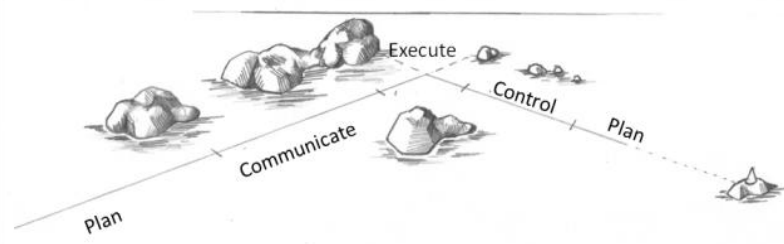

Figure 1: Graphical representation of the basic phases in DYNAV methodology.

\section{1 (a) Plan}

In the planning phase the navigator orientats himself. He needs to know where he is, and where he is not. Then he identifies where he wants to be after next turn or series of events. Then he assesses the constraints for this action and forms a simple plan on how to achieve it. Much of this planning can with advantage be done in advance before leaving the key but there is always need for orientation and adjustment to the real circumstances.

\section{1 (b) Communicate}

The plan will be broken down into a set of standard instructions based on the need of basic information. The navigator communicates his plan to the driver. The driver and navigator communicate by a closed loop protocol in order to make sure that both parts know that the message has been received and understood.

\section{1 (c) Execute}

During the execution phase it is preferred that the driver has as much delegated responsibility as possible to lighten the workload of the navigator. The driver reeds back to the navigator as he is closing in to the waypoint and speak out load what's he's doing. The navigator watches and follows the development.

\section{1 (d) Control}

When the turn has been made the navigator checks if it turned out the way they anticipated. In this control phase lays a crucial safety barrier. By checking and comparing several types of data the crew create possibilities to identify errors in an early stage before they have implications on safety. This is a very important step to perform to achieve efficient error trapping, se 5.2(a).

\section{SUPPORT PROCESSES}

The basic methodology described above is just telling what main process to work with in which situation. We need to dress this up a bit more with an information scheme to fill, in order to make sense. What are the most essential parts a driver or helmsmen of a vessel need to know for safe navigation and wayfinding?

\section{$5.1 \quad$ STANDARD INSTRUCTIONS}

In DYNAV there are a set of standard instructions that gives the driver answers to following questions:

- Where they are going now

- Where and how to do the next turn

- Where they are going next

- Where they not should be

- How I know I'm safe

This information is communicated with a standard protocol. The navigator will give the driver this instruction and normally

- General briefing about the situation

- In what direction next turn will be (port or starboard)

- On what information cues the turn shall be executed

- Where there are dangers.

- The next course and how to control the outcome of the turn.

Equipped with this information the driver is able to conduct the next turn or the next moments. The navigator has the possibility to monitor the process without being overloaded with giving instructions and monitoring the outcome of the turn simultaneously which lower his mental workload.

Dobbins D. et. al. 2010. proposes a model for High Speed Craft Command And Control (HSC3). This model shows graphically how the information is gained and utilized by the crew.

\section{2}

\section{SITUATION ASSESSMENT}

The Situation Assessment Process (SAP) is the procedure of checking and cross-checking sources of location and environmental information to inform the navigators Situational Awareness and enhance the certainty of the crafts current status within its surrounding/environment as well as other elements and their effect on the vessel.

Within the navigators requirement for Location Certainty it should be noted that it can be as important to know where the craft isn't, as it is to know where the craft is. 
The classical school of navigation suggests that one should know ones position at all times. This isn't possible as we are moving and the problem will be accentuated as the speed increases. In high speed navigation the movement needs to be taken account for as a navigational parameter.

The importance of the sources of information will change depending on the situation and environmental conditions. The cross checking of information sources within the SA process reduces the risk of errors and enhances the Navigators location certainty to facilitate the Plan phase of the DYNAV method.

Sources of location information:

- Visual

- Paper chart

- Radar

- Electronic chart

- Heading

- $\quad$ Course over ground (COG)

- Depth

- GPS

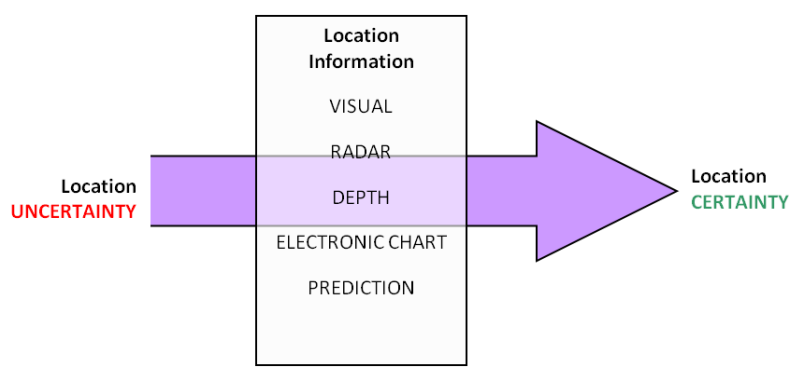

Figure 2: Contributing data sources to achieve location certainty.

\section{2 (a) Trapping errors}

The crew need to be able to identify their own mistakes, distorted or false data from the sensors before it has impact on safety. If the crew only is making its judgements mainly on one source of information the possibilities to scrutinise own actions or perceived data are slim. One tactic to enable scrutinising is to use many sources of information and multiple tactics for problem solving. Assault Navigation (2010) tries to show this with the Navigation Loop. Even though it implies that you should use more then one source of information, it doesn't show that you need to use them simultaneously. The key to error trapping is to get more than one set of data so that you can compare them. If there is inconsistencies in the data or in the outcome of the manoeuvre, depending on what control function the crew uses, it is to be considered a risk and the speed should be reduced or come to a halt.

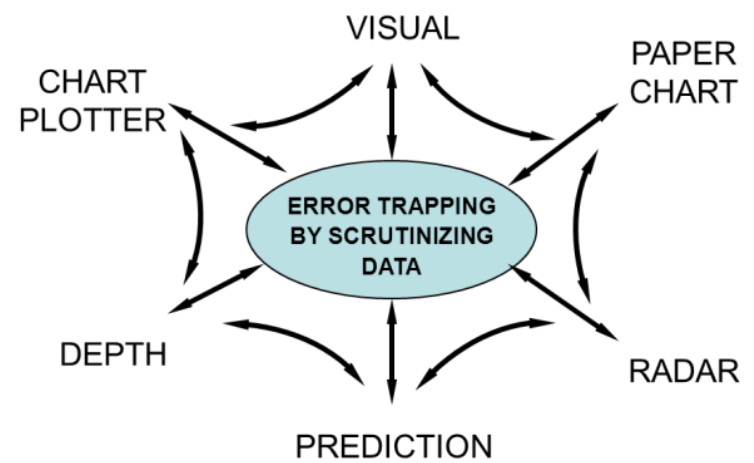

Figure 3: Error trapping by scrutinizing data

Error trapping or threat and error management (Dekker 2007 ) is to be seen as a part of everyday operation and must be successfully managed in order to avoid undesired states that leads to increased risk.

\section{2 (b) Sense Making}

Garry Klein has through a series of papers looked upon the concept of Sensemaking as an extension of Naturalistic Decision Making (NDM). Sensemaking is deliberate effort to understand events (Klein. et al 2007). SA is according to Endsley (1995) "The perception of elements in the environment within a volume and time and space, the comprehension of their meaning, and the projection of their status in the future". In Contrast sensemaking is an approach that describes the process of constructed data as well as meaning.

A closer look at DYNAV from a Sensemaking point of view will hopefully be covered in subsequent paper.

\subsection{DECISION MAKING}

It is assumed that the navigator will have pre-planned the route before starting the voyage. By doing this the navigator has made up the big plan that will help him achieve the over aim. In the pre-plan the navigator makes choices of route to go. This is based on how big a challenge he is willing to take on. The challenge is dependent of the complexity of the route matched with the crew and the crafts status and other (e.g. environmental) circumstances. The more challenging the route taken the more the navigator needs to go into detail in the pre-planning. With detailed pre-planning the navigator won't have as high mental work load as if he hadn't done any planning. The pre-planning is essential for efficient navigation, especially at high speed and/or in complex situations with time constrains. Knappen Rød (2007) Divides navigation into two phases, the planning phase and the execution phase where the planning is done ashore and the execution at sea. In this paper we name Røds planning phase pre-planning.

The pre-planning work, used as a tool, will help the crews' ability to assess the situation when it is happening. The crew needs to have a high level of SA in 
order to be able to make all the decisions necessary for successful navigation.

\section{3 (a) Nested Loop planning}

Within the PLAN phase the navigator will undertake two 'nested' planning loops:

\section{Operational planning loop}

This loop is to ensure that the decisions made for next turn point and subsequent transit leg are safe, efficient and support the achievement of the overall aim.

2. Tactical planning loop

The Tactical planning loop, or forward-planning as it has also been called, isn't as straight forward as the operational planning loop but it is still crucial to successful navigation. The forward planning is a way of thinking ahead. The actions undertaken here will effect were and how the craft ends up after the next couple of turns. Therefore the navigator needs to understand how the required outcome for say the next three turns, and actions are adjusted to support the safe and effective outcome for the subsequent turn(s).

The forward-planning is an ongoing process at all times and underpins or provides constraints for the operational planning.

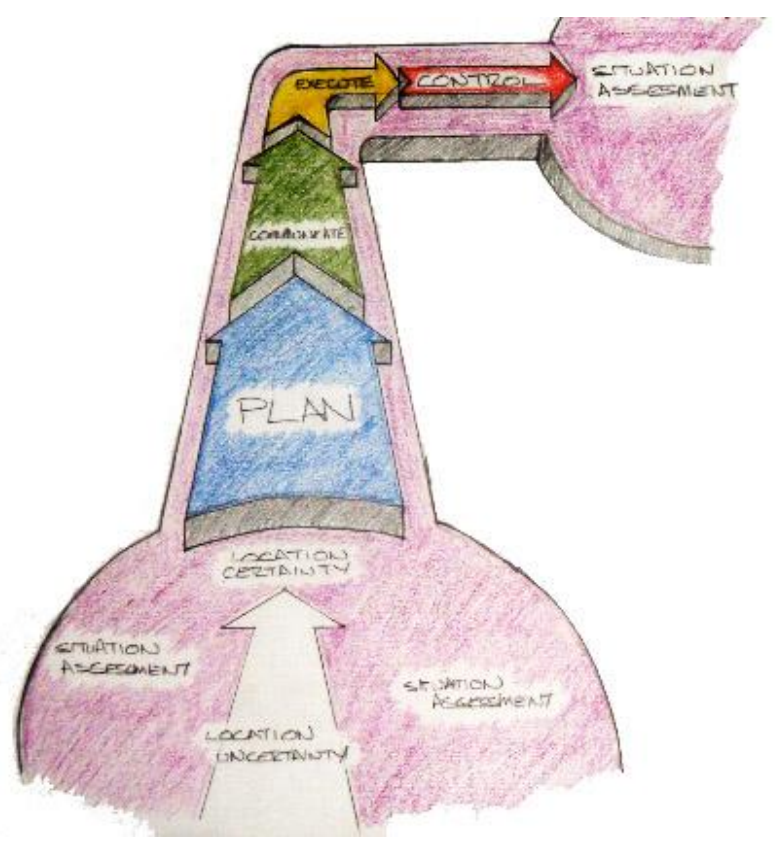

Figure 2: Graphical representation of the inclusion for Situation Assessment within the DYNAV methodology

\section{INFORMATION DISPLAY}

6.1 PAPER CHARTS VS. ECDIS
There are a couple of constraints when it comes to the plotters that are available on the market today. The most obvious problem is that they are not an integrated part in the system as a hole. The bridge has a lot of diversified equipment that is very far from reaching its potential of supporting the crew. The paper chart has some futures that no electronic system is getting close to when it comes to performance:

- You can write on it

- You can’t fail starting it up.

- It runs without power.

- You don't need to read the manual before using.

- Very high resolution and thus containing much more information than even a screen with the same physical size.

- Large physical size which enables you to overlook a large area and by that aiding orientation.

The chart also enables you to do your planning. Today no electronically system to our knowledge allows you to make preparations for navigation to the same level of detail as the paper chart does.

\subsection{MULTI-MODAL DISPLAYS}

If in the future a developed methodology gains recognition outside the organisations already using it, it can have positive implications when in comes to standardisation and design of multimodal displays that aims to provide the right information at the right time in the right place. But to do this job there has to be grate understanding in what the tasks are and how they are performed. The concept of DYNAV can give guidance in this process if it will be combined with further research.

\section{CONCLUSIONS}

The aim of this paper is to give a description of a navigation methodology empirically developed and why it has come to look as it does. The methodology aims to provide enhanced operational effectiveness, safety and interoperability between fast (Assault if mil/defence) craft by the development of an internationally recognised, standardised dynamic navigation methodology.

\subsection{DYNAV METHODOLOGY}

DYNAV as a concept is designed to be simple, easy to learn and provide efficiency. With DYNAV a navigation pair, i.e. driver and navigator with equal competence, are able to undertake tasks that normally is being done with a 
lot more personnel on the bridge. DYNAV also enable the crew to make safe transits through constrained areas thane would have been possible with traditional navigation. DYNAV is a flexible methodology and has been successfully implemented in HSC and Hovercrafts as well as classic slow going vessels.

\subsection{CONTINUEING DEVELOPMENT}

The DYNAV methodology as such need to be further developed by scientific research. There are many issues that need to be investigated further. There is a set of new technologies coming to us and they will give us both new possibilities but also cause problems when implemented. It is of grate importance to understand what, why and how the navigation tasks are undertaken to be able to foresee the effects of introduction of new technologies. There is a need for understanding the Situation Assessment process and how it supports decision making in order to continue the development of both the methodology as such and display development.

\section{REFERENCES}

1. Dahlman, J., Forsman, F., Sjörs, A., Lützöft, M., Falkmer, T. Eye-Tracking during High-Speed Navigation at Sea. In proceedings of 6'th annual meeting of Society for Human Performance in Extreme Environments, New York, NJ, Sept. 21-22. 2008

2. Dobbins, T. et Al. High speed craft command \& control: a model of navigation and crew interaction to enhance performance and safety in the harsh shock and vibration maritime environment, Royal Institute of Navigation, In proceedings of RIN NAV10 conference, 30/11/2010.

3. 10 Squadron Poole Dorset, Assault Navigation Precis, Ministry of Defence, may 2010.

4. Knappen Rød, B. Designing for high-speed ships Doctoral thesis at NTNU, 2007.

5. Klein, G. Philips, K. Rall, E. Peluso, D. A DataFrame Theory of Sensemaking. Expertise Out of Context, In Proceedings on the Sixth International Conference on Decision Making. 2007.

6. The International Regulations for Preventing Collisions at Sea, International Maritime Organisation. 2003.

7. Försvarsmakten, Brygginstruktion för Marinen, Försvarets bok och blankettförråd, 2003.

8. Dekker S. Lund, J. From Threat and Error Management (TEM) to Resiliance. Lund University School of Aviation. May 2007.

\section{AUTHORS BIOGRAPHY}

Fredrik Forsman, Capt, holds the current position of Head of Training at The Swedish Sea Rescue Society. He is also a Part of the Human Factors Group at Chalmers University of Technology as $\mathrm{PhD}$ Student. $\mathrm{He}$ is responsible for the development of the training organisation for the crews in the Sea Rescue Society. His previous experience includes training of High Speed Navigation Crews in the Swedish Amphibious Corpse where he developed methodology for High speed navigation and pedagogies.

Joakim Dahlman, MD, Phd, holds the current position of senior lecturer and $\mathrm{PhD}$ in medicine at Chalmers University of Technology.

Trevor Dobbins, Phd, holds the current position of Director at STResearch Ltd. He has published widely on HSC Human Factors and is the principal author of the High Speed Craft Human Factor Design Guide. His previous experience includes working for the MOD as a human Sciences Advisor for amphibious operations and as a Researcher at the University of Chichester 


\section{FIGURES}

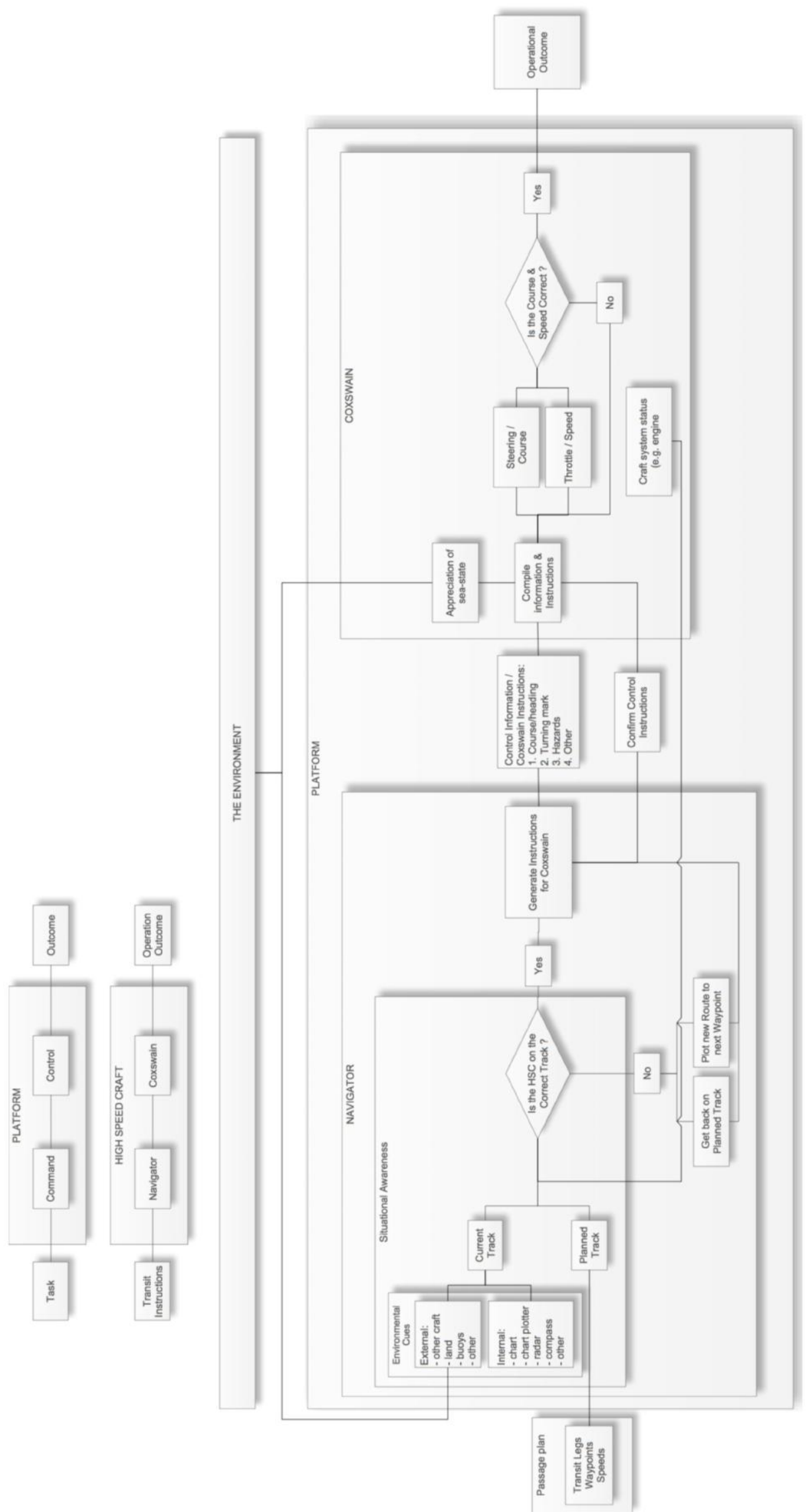

Figure 1. Draft HSC Command \& Control (HSC3) Model. (Dobbins, Dahlman, Stark; 2009) 